\title{
BEST-SELLERS E ENSINO DE LITERATURA: MERCADO EDITORIAL, LEITORES E ESCOLA
}

\section{BEST SELLERS AND LITERATURE TEACHING: EDITORIAL MARKET, READERS AND SCHOOL}

\author{
Luzimar Silva de LIMA* \\ Shirlei Marly ALVES**
}

\begin{abstract}
Resumo: Este trabalho tem como objetivo problematizar as relações entre os best-sellers da cultura de massa como produto do mercado editorial, os leitores e a escola. Focalizamos, portanto, as conjecturas e a recepção que essa literatura alcança em espaço escolar quanto ao ensino de literatura, bem como as conotações de que se reveste o termo best-seller por ser oriundo do mercado editorial, considerando as perspectivas do consumo, dos leitores e da escola. Para tanto, foram basilares os estudos de Petit (2009), Sodré (1988), Candido (1998), Cosson (2014), Reimão (1996), Calvino (1993), entre outros. Em linhas gerais, os autores discutem a literatura enquanto prática de liberdade, de acesso aos diferentes níveis e modalidades da cultura, bem como o conceito de cânone e implicações com os best-sellers, considerando as escolhas dos leitores para além do que a escola indica como leitura. Nesse sentido, o mercado editorial influencia fortemente o consumo de muitas obras, dentre as quais um maior destaque é dado aos bestsellers da cultura de massa, cada vez mais presentes no repertório de leituras do jovem leitor. Dessa forma, partir do conhecido para o desconhecido pelo aluno pode ser um importante ponto de partida do ensino de literatura na escola. Assim, vislumbramos o reconhecimento dos leitores e suas preferências, bem como a necessidade de um olhar para a arte literária a partir das perspectivas política e democrática quando a questão é leitura literária na escola.
\end{abstract}

Palavras-chave: Literatura. Best-sellers. Mercado editorial. Leitores. Escola.

\begin{abstract}
This paper problematizes the relation among mass culture best-sellers, as products of the editorial market, readers and schools. The focus is on theories and the reception that these works have achieved in literature classes and also on the connotations that the term best sellers covers - an expression from the editorial market, considered from the perspective of consumption. The paper is anchored on Pettit's, Sodré's, Candido's, Cosson's, Reimão's, Calvino's, and other authors' ideas. These authors discuss literature as a practice of freedom, as an access to different levels and modality of culture; they also review the concept of canon and the implications for best sellers, considering readers' choices, which go beyond what schools recommend as reading. In this sense, the consumption of many works is strongly influenced by the editorial market, and greater prominence is given to best sellers of mass culture, which is increasingly present in young readers' reading repertoire. It is argued that moving from what students know to what they do not know can be an important starting point to teach literature at school. Readers' preferences, as well as viewing literary art from a political and democratic perspective should be in issue when the question is the literary reading at school.
\end{abstract}

Keywords: Literature. Best sellers. Editorial Market. Readers. School.

\footnotetext{
* Doutoranda em Literatura na Universidade Federal do Piauí (UFPI). E-mail: luzilii @ hotmail.com.

${ }^{* *}$ Professora da Universidade Estadual do Piauí (UESPI). Doutorado em Letras pela Universidade Federal de Pernambuco (UFPE). E-mail: shirlei.alves42@ hotmail.com.
} 


\section{Introdução}

O cenário contemporâneo faz descortinar uma nova visão sobre os leitores quando se trata do ensino de literatura, sobretudo pelo fato de que o mercado editorial tem uma forte representatividade em relação ao que o público infantil e juvenil lê hoje. Nesse universo de leitura, a política de investimento das editoras nos livros de categoria best-seller da cultura de massa vive a efervescência dos campeões de vendas nas listas de leituras estampadas em importantes revistas. Por outro lado, no âmbito da escola, essas obras, muitas vezes, são descreditadas justamente em função da quantidade de vendas, como se isso fosse suficiente para lhes negar qualidade.

Nesse contexto, os jovens leitores, seduzidos pelo universo dessas leituras, mantêm-nas como uma prática contínua e duradoura. Interessante também ressaltar que tais obras irrompem os espaços da leitura solitária e chegam às escolas partilhadas pelos alunos, com apreço e gratuidade, nas conversas de corredor, nas trocas de impressões e indicações na hora do recreio, contagiando, assim, um número expressivo de leitores. No entanto, ao chegarem em ambiente de ensino, poucas vezes, ganham visibilidade, sendo, geralmente, rejeitadas por professores, que não as consideram "literatura", a partir de diversos argumentos que as tornam impróprias para se tornarem alvo de atenção didática ${ }^{1}$.

Assumindo uma concepção segundo a qual é necessário discutir as diretrizes para a seleção de obras literárias na escola sem rigidez e preconceitos, tendo o aluno e suas experiências de leitura como ponto fulcral, este trabalho vislumbra ações metodológicas que reconheçam a legitimidade da leitura de best-sellers na escola. Propõe-se que as subjetividades dos alunos (intentos, preferências, experiências) ganhem espaço, para que, a partir da fruição do popular (best-sellers), o erudito (o cânone) seja fruído como uma consequência natural, sem que uma dicotomização enrijecida ou não fundamentada relegue os best-sellers à condição de literatura de valor nenhum, à revelia de diversos estudos que apontam os benefícios que podem trazer para a formação do leitor literário. Nesse sentido, visa-se a um reconhecimento dos leitores da literatura de cultura de massa efetivamente como leitores de literatura, superando-se a visão de que tal status se associa apenas à leitura dos clássicos - tradicionalmente exclusividade do ensino de literatura na escola. Portanto, propomos uma política de reconhecimento e aproveitamento dessas leituras como válidas no processo de formação de leitores literários.

\footnotetext{
${ }^{1}$ Paraliteratura, literatura trivial, subliteratura, literatura de entretenimento, de massa ou de mercado são algumas denominações que essa literatura recebe. Cf. Reimão (1996). Revista Graphos, vol. 22, n² 2, 2020 | UFPB/PPGL | ISSN 1516-1536
} 


\section{Best-sellers: Conceito e implicações com o mercado editorial}

Um questionamento necessário diz respeito às obras que fazem parte da lista de preferências dos atuais leitores de diversas faixas etárias, sendo flagrante a presença de livros que não estão inseridos no cânone - privilegiado quando o assunto é literatura. Se fizermos uma pesquisa nas revistas semanais, certamente perceberemos que as pessoas têm lido bastante, mas não obras clássicas. O cenário contemporâneo tem mostrado uma leitura massificada de bestsellers; estratégias editoriais têm alcançado e fascinado jovens leitores.

A título ilustrativo, o site da revista Veja apresenta a lista dos livros mais lidos pelo público infantojuvenil até 29 de abril de 2020, com forte presença dos best-sellers da cultura de massa, evidenciando os esforços da indústria cultural e do mercado editorial como propulsores dessas obras e da propagação que alcançam. Os dados apresentados no site da revista estão reproduzidos no quadro 1 , a seguir.

Quadro 1 - As obras mais lidas segundo lista da Veja

\begin{tabular}{|c|c|}
\hline TÍTULO DO LIVRO & POSIÇÃO \\
\hline Coleção Harry Potter (J.K. Rowling) & $1^{\circ}$ \\
\hline Um anjo de mochila azul (Diogo Almeida) & $2^{\circ}$ \\
\hline Anne de Green Gables (Lucy Maus Montgomery) & $3^{\circ}$ \\
\hline A seleção (Kiera Cass) & $4^{\circ}$ \\
\hline A elite (Kiera Cass) & $5^{\circ}$ \\
\hline Harry Potter e a pedra filosofal (J .K. Rowling) & $6^{\circ}$ \\
\hline A escolha (Kiera Cass) & $7^{\circ}$ \\
\hline O pequeno príncipe (Antoine de Saint Exupéry) & $8^{\circ}$ \\
\hline As crônicas de Nárnia (C. S. Lewis) & $9^{\circ}$ \\
\hline Por lugares incríveis (Jennifer Niven) & $10^{\circ}$ \\
\hline Harry Potter e a câmara secreta (J. K. Rowling) & $11^{\circ}$ \\
\hline Harry Potter e o prisioneiro de Azkaban (J. K. Rowling) & $12^{\circ}$ \\
\hline A herdeira (Kiera Cass) & $13^{\circ}$ \\
\hline Malala - a menina que queria ir para a escola (Adriana Carranca) & $14^{\circ}$ \\
\hline A Coroa (Kiera Cass) & $15^{\circ}$ \\
\hline Harry Potter e o cálice de fogo (J. K.Rowling) & $16^{\circ}$ \\
\hline O mundo de Sofia (Jostein Gaarder) & $17^{\circ}$ \\
\hline A rainha vermelha (Vitória Eveyard) & $18^{\circ}$ \\
\hline A cinco passos de você (Rachael Lippincott) & $19^{\circ}$ \\
\hline Espada de vidro (Vitória Eveyard) & $20^{\circ}$ \\
\hline
\end{tabular}

Fonte: <https://veja.abril.com.br/livros-mais-vendidos/infantojuvenil/>. Acesso em 28 de abril de 2020.

Conforme o quadro 1, percebe-se a estratégia do mercado editorial em publicar obras em sequência, no sentido de dar continuidade a obras que tem grande aceitação de mercado. É nesse contexto que situamos a compreensão e o conceito de best-seller na contemporaneidade: autores caem no gosto do público e são reproduzidos de modo serial pelas editoras. É uma via de mão 
tripla, sendo beneficiados autores, editoras e leitores, embora o mais comum seja o pensamento de que os leitores se tornam apenas "consumidores", em virtude de as obras serem consideradas apenas como produtos de um plano de marketing, focado, portanto, apenas na venda. Nesse sentido, a leitura não propiciaria a fruição estética e muito menos a experiência de descoberta que a literatura canônica promove.

[A] personalidade construída a partir da generalização da mercadoria, quando entra no universo da escrita (o que é um fenômeno deste século), o faz com vistas ao destinatário, que é o leitor-massa, faminto de uma literatura que seja especular e espetacular. Autor e leitor perseguem a representação do show da vida, incrementado e amplificado. Autor-massa e leitor-massa buscam a projeção direta do prazer e do terror, do paraíso do consumo ou do inferno do crime - uma literatura transparente, no limite, sem mediações, uma literatura de efeitos imediatos e especiais, que se equipara ao cinema documentário, ao jornal televisivo, à reportagem ao vivo. (BOSI, 2002, p. 249).

Conforme as palavras de Bosi, o leitor-massa atende mais diretamente aos sabores proporcionados pela leitura, por ser ela criada a partir de mecanismo de facilitação que requer um estímulo imediato. No entanto, há que se reconhecer que essa transparência o faz vivenciar experiências diversas, ainda que facilitadas, muitas das quais garantem-lhe como leitor assíduo dos best-sellers da cultura de massa, o que não se configura como risco e nem o torna menos leitor por não ler os clássicos.

Percebe-se que a carga negativa atribuída a essas obras se dá, sobretudo, pelo caráter mercadológico, como se, por esforço quantitativo, a qualidade nunca seja alcançada. Isso se deve, principalmente, às razões conceituais de sua natureza. Os best-sellers são vistos muito mais como mercadoria (um produto barato) do que como livros cuja configuração implica leitor e leitura. A lógica de definição parece seguir a lógica da

economia de consumo [...] inseparável desta invenção de marketing: a busca do lucro pelo volume e pela prática dos preços baixos. Pôr os produtos ao alcance das massas: a era moderna do consumo é condutora de um projeto de democratização do acesso aos bens mercantis, não aos bens culturais em sentido pleno - popular e erudito" (LIPOVETSKY, 2007, p. 28, grifo nosso).

Ao se ater a critérios de definição, os best-sellers situam-se em um terreno em que imperam as diretrizes do mercado editorial. Para Reimão (1996), o termo ainda carrega imprecisões, visto que pode ser compreendido de forma literal: "Best-sellers indica aqui os livros mais vendidos de um período em um local. Nesse sentido, é uma expressão quantitativa e comparativa, e que diz respeito a vendas" (REIMÃO, 1996, p. 23). Rossato (1994) discorre sobre o que se entende como best-seller, referindo-se aos franceses, que deram o nome genérico de paraliteratura (paralitératture) para o que nós convencionamos chamar de literatura da massa, ou seja, best-seller, que vende milhões de exemplares e enriquece seus autores e editores 
com textos considerados "dirigíveis" e "envolventes", próprios para o entretenimento dos leitores ávidos por uma história. Isso não significa que uma obra de literatura culta não possa tornar-se também um best-seller, ao obter uma grande receptividade popular.

Segundo Lima (2015), o livro denominado best-seller é fruto da cultura de massa, que começou a se consolidar no século XIX e se tornou um gênero à parte, menosprezado pela elite e pelas escolas, porém de grande receptividade popular.

Muitos estudos têm sido desenvolvidos com relação à leitura de best-sellers, tendo em vista os holofotes mercadológicos sobre esses livros, garantindo, inclusive, o rápido e fácil acesso do público. Nesse sentido, estratégias são usadas para garantir as vendas e torná-los facilmente agradáveis ao público. Reimão (1996) explica que essa acessibilidade se deve ao próprio caráter de facilitação econômica e psicológica. Aquela, porque se reveste no barateamento do produto; e esta porque se trata de obra palatável e de fácil assimilação.

A autora ainda traça algumas considerações sobre a abordagem teórica dos best-sellers marcada mais por aspectos negativos que positivos. Destacam-se estudos que os tomam como degrau para outras leituras mais densas; como experiência de regressão e hiato na consciência crítica do leitor, privado do acesso ao cânone; como um filtro cuja capacidade se reveste na eliminação dos malefícios da indústria cultural a partir da rejeição e seleção exercida pelo público consumidor. Portanto, funciona como espécie de defesa contra os efeitos da indústria cultural, defendendo o acesso à literatura erudita.

Para além dos diferentes julgamentos sobre sua qualidade, é perceptível a crescente aceitação e apreço que as obras da cultura de massa têm despertado, tornando-se, assim, campeões de venda (best-sellers), atraindo uma legião de leitores, dentre os quais destacamos mais especificamente o público infantojuvenil, visto que lançamos um olhar para o contexto escolar, onde se pode tirar proveito dessas leituras ao se reconhecer os seus leitores. Fechar os olhos para os best-sellers e desprezá-los como leitura trivial, dirigível e sem novidade não fará com que os alunos deixem de lê-las; ao contrário, tomá-las como ponto de partida para ampliar as leituras é um caminho bastante iluminador para a formação de leitores em espaço escolar. Afinal, a rigor, nenhuma leitura é descartável no sentido de nada acrescentar aos leitores.

\section{Best-sellers e o ensino de literatura: o jovem e suas preferências}

Temos visto um mercado editorial forte, com estratégias de marketing direcionadas ao público consumidor de obras que se tornam best-sellers. Nesse contexto de forte presença e acessibilidade promovidos pela política de consumo, grande parte da crítica torce o nariz por 
defender que o fato de um livro de ficção ser o mais vendido não significa que apresente valor literário. Entretanto, ao negar-lhes algum valor, desconsideram-se as vivências e experiências dos seus leitores. Nesses últimos anos, a saga Harry Potter, por exemplo, conquistou uma legião de leitores e expectadores no cinema, uma realidade crescente entre grande parte dos jovens. Essa empolgação é avaliada positivamente por Ângela Maria Lignani, no que diz respeito ao campo pedagógico:

Acredito que não se possa simplesmente desprezar Harry Potter que, no mínimo, está provocando uma transformação no âmbito da leitura [...] O educador não receptivo às novidades que assediam o mundo infantil perde a oportunidade da interação em que acontece a aproximação de amizade, de cumplicidade que, às vezes, também deve entrar como componente na relação professor/aluno. (LIGNANI, 2004, p. 125).

Não somente o fenômeno Harry Potter como também outros best-sellers têm seduzido multidões de leitores cujas práticas de leitura não se iniciam e se encerram em suas casas e ciclos de amizades externos à escola. Elas ultrapassam as experiências individuais e são partilhadas dentro do contexto escolar, muitas vezes de forma clandestina.

Nesse contexto, questiona-se como e por que dar visibilidade a essas leituras e leitores, o que, necessariamente, obriga a se pensar o acolhimento e o tratamento que os textos contemporâneos recebem na escola, instituição que, historicamente, sempre valorizou a historiografia construída do passado para o presente e os autores consagrados pela crítica, pelos estudos clássicos e pelos livros didáticos.

Importante ainda considerar que o atual leitor, muitas vezes, não escolhe uma obra por ela ser um clássico, mas porque se identifica com a trama narrativa, com o drama de um personagem e ainda porque, no seu grupo de relações, a obra está sendo comentada e valorizada.

Há uma prática de resistência no que se refere à visibilidade do aluno como leitor e como instância primeira do processo da leitura. Geralmente, diante de currículos prontos, os professores excluem os leitores reais com suas leituras consolidadas, sobre as quais nem sempre podem se expressar: "A escola ensina a ler e a gostar de literatura. Alguns aprendem e tornamse leitores literários. Entretanto, o que quase todos aprendem é o que devem dizer sobre determinados livros e autores, independentemente de seu verdadeiro gosto pessoal" (ABREU, 2006, p. 19).

Para Cosson (2014), a literatura requer dos seus leitores uma leitura plural e diversa, para que, assim, tenhamos uma escola plural e democrática, o que implica em se ter o gosto e a experiência do aluno como um fator a levar em conta na seleção de textos para leitura. Isso significa respeitar as diferenças e os diversos valores que justificam as escolhas da comunidade de leitores. No entanto, “as posições assumidas pelos professores são as mais diversas. Há 
aqueles que sequer admitem discussão e continuam a afirmar a essencialidade do cânone e da tradição" (COSSON, 2014, p. 94). Tal posição evidencia que

[n]a média, os professores assumem uma postura autocrática e definem as leituras para seus alunos tendo como horizonte apenas as suas próprias leituras, em um conjunto que se alterna entre obras de autoajuda e obras canônicas, incluindo um pouco de tudo e um tanto de nada. (COSSON, 2014, p. 95).

A escola precisa estar aberta às questões apresentadas, visto que muitos alunos podem ter convicção de lerem literatura quando em contato com os best-sellers. No entanto, em grande parte das salas de aula, nem se cogita trazer essas percepções para análise e discussão, a fim de se promover uma ampliação da experiência desses leitores. O ideal seria reconhecê-los em suas preferências e, a partir disso, refletir sobre o valor literário dessas obras para diferentes comunidades de leitores. Isso requer um trabalho pedagógico que não negue o leitor como leitor pelo fato de ler best-sellers, corroborando uma prática que se legitima pela concepção de que digno de tal alcunha é quem lê o cânone, e apenas este.

É preciso considerar que o perfil do leitor mudou e que essas novas preferências são elementos constituintes dessa nova identidade, constituindo também outras formas de socialidades.

\begin{abstract}
Mas o que leva os jovens optarem pela leitura de best-sellers? O grande incentivo concorrente é a interação que conseguem assumir com a leitura desses textos, interação durante a leitura silenciosa e interação nas práticas cotidianas com os amigos que demonstram nessas conversas verdadeira adoração por esse tipo de literatura. Com a leitura dos best-sellers, os jovens leitores encontram o prazer da leitura e a relação de alteridade com seus incentivadores, representados pelos amigos. (LIMA, 2015, p.193).
\end{abstract}

Segundo Calvino (1993), um clássico deve ser lido porque estabelece uma relação pessoal com quem o lê, do contrário, se reservará a recusa. A relação que deve existir não é a de dever ou respeito, mas de amor. Contrariamente a essa visão, na escola, o sabor do deleite ou da relação pessoal é substituído por um dever, obrigando-se o aluno a conhecer, bem ou mal, um grande número de autores clássicos, quer agradem ou não. Assim, o prazer experimentado com a leitura de best-sellers, muitas vezes, desaparece quando ao leitor é imposta a obra do cânone. Best-seller é escolha, identificação, apreço, deleite, prazer, entre tantas outras funções experienciadas por seus leitores. Enquanto o cânone, muitas vezes, se reveste de imposição, obrigação, frustração, recusa.

Calvino (1993, p. 13) ressalta que "a escola é obrigada a dar-lhe instrumentos para efetuar uma opção: mas as escolhas que contam são aquelas que ocorrem fora e depois de cada escola", reforçando a liberdade que experimenta o aluno quando, fora da instituição escolar, pode aderir 
ao que lhe toca a sensibilidade ou a curiosidade, como o é caso dos best-sellers. Por essa razão, ao se reconhecer que as escolhas funcionam como moventes dos leitores, elas devem ter também visibilidade no ensino de literatura.

A dupla presença dos best-sellers e das obras canônicas em horizonte escolar, com os ingentes desafios que lançam à escola como instituição encarregada de formar leitores, levanta um importante questionamento: como administrar tais leituras de modo a não perder de vista a valorização dos clássicos? Essa é uma questão que, hoje, deve permear as práticas de sala de aula quanto ao ensino de literatura.

Riolfi et al. dão um encaminhamento bastante questionável, no qual se verifica uma estratégia de descredenciamento dos best-sellers frente ao cânone literário:

Poderíamos nos contrapor à presença dos chamados Best-sellers - e os similares - nas
aulas de Língua Portuguesa com base em uma oposição simples: se deles já se ocupam
o marketing editorial, a mídia, as livrarias, a internet (eles são sempre os primeiros à
mostra), para que o professor precisa se ocupar dele também? De fato, essa seria uma
razão plausível, mas simplesmente ignorá-los significaria não levar à sala de aula a
discussão sobre as razões, sejam textuais, sejam históricas de esses livros não
permitirem o acesso ao que é específico do literário. Seria necessário, em um
estágio avançado de leitura em sala de aula, discuti-los, para demonstrar, por meio
de análises, como as estratégias discursivas se repetem nesse tipo de obra.
(RIOLFI et al., 2014, p. 79, grifos nossos).

As autoras apresentam algumas razões para que essas leituras e o trabalho com elas em sala de aula sejam evitados, sendo que, ao tomarem uma posição favorável à inserção na escola, enfatizam que o trabalho de contemplação de best-sellers em sala de aula é para desqualificálos no confronto com as obras consideradas, de fato, literárias - os clássicos.

Orientação diferente é dada por Regina Araújo, ao propor uma forma diferente de abordar os clássicos em correlação com os best-sellers:

\footnotetext{
A marginalização da chamada "literatura de massa" não é o mais aconselhável, já que essa atitude não contribui para despertar o encantamento dos alunos pelos livros. O que deve ser revisto é a abordagem que é feita dos clássicos em sala de aula. $\mathrm{O}$ professor poderia partir das leituras conhecidas dos jovens - como os Best-sellers para, posteriormente, apresentar novas leituras. (ARAÚJO, 2014, p. 82).
}

Acreditamos, nesse sentido, que o trabalho com literatura deve, sim, ser prioridade, garantindo-se, como Candido (1988), um direito do leitor, mas isso não implica em desqualificar a liberdade de escolha própria desse mesmo leitor. Quanto à literatura da cultura de massa, é possível mostrar que elas têm o seu valor (o qual pode não ser o mesmo da literatura dita culta), propiciando a ampliação do universo de leituras. 
É possível tirar muito proveito dessas leituras com uma abordagem que acolha as leituras no contexto de subjetividades dos alunos e que ofereça um percurso metodológico favorável a isso. Sob tal ótica, acredita-se que os best-sellers funcionam como uma leitura "estimuladora do gosto e do hábito da leitura, adquire o sentido de degrau de acesso a um patamar mais alto onde o entretenimento não se esgota em si, mas traz consigo um alargamento da percepção e um aprofundamento da compreensão das coisas do mundo" (PAES, 2000, p. 28)

Apenas pensar nos aspectos negativos e ter os best-sellers como ameaça ao texto literário da literatura erudita são fatores que não resolverão esse impasse, ou seja, os problemas do ensino de literatura não serão resolvidos se os best-sellers forem proibidos ou deixarem de fazer parte da escola pelas experiências e gostos dos alunos. Isso não impedirá que sejam lidos, tampouco de fazerem parte das leituras preferidas dos adolescentes. Afinal, é fora dela que os alunos mais têm acesso a essa literatura e a pratica como leitura dissoluta de imposições.

Ações articuladas e medidas devem ser pensadas, no sentido de não contrariar ou impor leituras que, inicialmente, serão negadas pelos alunos, afinal, eles já fazem por iniciativa própria suas leituras de gosto pessoal. A metodologia dada ao texto literário na escola precisa ser repensada.

Quando a escola perceber que "não há obras boas e ruins em definitivo. O que há são escolhas - e o poder daqueles que as fazem. Literatura não é apenas uma questão de gosto: é uma questão política" (ABREU, 2006, p. 112), então haverá um trabalho plural e dialógico em que o leitor se sentirá reconhecido em um contexto de novas oportunidades leitoras, ampliando gostos pelo contato com os outros alunos e com o professor, a partir da partilha de suas leituras como experiência pessoal, coletiva, dialógica, plural, política e democrática.

Riolfi et.al (2014, p. 96) explicam que "nem todo livro de ficção merece ser lido, estabelecemos que livros dirigidos a um consumidor que os escolhe pelo critério do entretenimento negam, em sua constituição, o próprio ser da literatura". Com uma visão diferente, Abreu (2006) salienta que muitas pessoas leem e compram best-sellers por julgarem ser produções literárias de alto valor ou porque essas obras lhes causam divertimento e emoção. Parece inevitável o caráter ameaçador dessas obras para muitos estudiosos e professores, no sentido de que compreendem que quem lê best-sellers da cultura de massa nunca lerá um clássico.

Entretanto, como você já deve saber, a opinião de professores e intelectuais sobre eles não é das melhores. Quando se trata dos melhores livros do século, os eruditos esforçam-se para lê-los e, sobretudo, para ter o que dizer sobre eles, pois isso é sinal de distinção e os coloca no topo da intelectualidade. Quando se trata de Bestsellers, ocorre justamente o inverso: dizem, galhardamente, que não leram e que, mesmo assim, não gostam. (ABREU, 2006, p. 18). 
Conforme já afirmamos, a literatura de cultura de massa tem valor discutido no cenário de leituras do brasileiro. A recriminação a essa literatura é reflexo social e alastra-se a todos os espaços, discutido, principalmente, quando o assunto é a escola. Desqualifica-se o fator leitura pelo pouco prestígio que apresenta e pela ideologia crítica dominante que a insere no rol de paraliteratura. Mas, há estudos que contestam tais afirmações por conceberem a leitura como ato de construção de conhecimento e de terem sua validade por oferecerem algum ganho, por mínimo que seja; isto é, nenhuma leitura é descartável, no sentido de nada acrescentar ao leitor. Ligia Dumont esclarece que

\begin{abstract}
[a]lguns combatem ardorosamente a literatura de massa, taxando-a de alienadora e culpando-a de não iniciar o leitor a observar e questionar os problemas que o circundam, trazendo, pelo contrário, a acomodação. Em contrapartida, existe uma ala mais moderada, que mesmo reconhecendo que essa literatura não possui os padrões desejáveis da literatura como arte informativa e enriquecedora sua leitura permite, através da ótica de cada leitor, de seu contexto, que algo se aproveite, por ínfimo que seja vindo então a acrescentar informação a sua vivência [...] quanto mais ler, mais informações o sujeito possuirá para discernir em situações em que se lhe presente no futuro. (DUMONT, 2000, p. 167).
\end{abstract}

Os defensores atestam uma validade que, de fato, existe e deve ser percebida pela escola. Temos um público leitor em formação que é, em grande parte, um assíduo leitor de best-sellers. O consumo acelerado de grande parte dessas escrituras faz o mercado editorial investir sempre mais. A receptividade popular permite a esse tipo de mercado seguir padrões ou receitas de uma obra, constituindo um grande número de exemplares vendidos e a produção de obras em séries, como as sagas, por exemplo. As subjetividades dos leitores mudaram, novos horizontes surgiram.

Sob essa perspectiva de novos horizontes e com uma visão mais receptiva, Sodré (1988) afirma que, nos best-sellers da cultura de massa, os ingredientes que os tornam tão receptivos são os conteúdos fabulativos em cuja mobilização da imaginação dos leitores é acionada, causando sensibilidade. As condições de produção desses textos são presididas pelo mercado e não pela escola. Por essa razão,

[s]e o best-seller é resultado do processo de industrialização e efeito da ação capitalista sobre a cultura, é preciso levar em conta também que esse tipo de narrativa tende a constituir-se em "campeão de vendas" porque se configura uma poderosa estimuladora de leitura, isto é, tem o poder de mobilizar o olhar e estimular a imaginação do leitor consumidor. O fascínio duradouro desta literatura indica que não se pode analisá-la com uma visão simplista e redutora, limitando-a ao campo de efeito de estratagemas mercadológicos ou como subproduto da literatura culta. (PAZ, 2004, p. 2). 
A acessibilidade aos best-sellers pelo mercado editorial torna-se mais eficaz; poderíamos dizer que a obra é massificada. Talvez por isso o desprestígio, tendo em vista que a literatura de massa é vista por grande parte da crítica como uma literatura de valor nenhum em que o fator quantidade não gera qualidade. Está sempre em um campo de resistências, sobre isso Culler (1999, p. 52) revela que "a cultura popular é feita da cultura de massas. A cultura popular é feita de recursos culturais que se opõem a ela e, desse modo, é uma cultura de luta, uma cultura cuja criatividade consiste em usar os produtos da cultura de massas. "

A lógica que segue em curso é o valor de mercado, cujo empenho democratiza essa literatura, tornando-a direito. De acordo com Antônio Candido,

[a] luta pelos direitos humanos abrange a luta por um estado de coisas em que todos possam ter acesso aos diferentes níveis da cultura. A distinção entre cultura popular e cultura erudita não deve servir para justificar e manter uma separação iníqua, como se do ponto de vista cultural a sociedade fosse dividida em esferas incomunicáveis de fruidores. Uma sociedade justa pressupõe o respeito dos direitos humanos, e a fruição da arte e da literatura em todas as modalidades e em todos os níveis e em um direito inalienável. (CANDIDO, 1998, p. 191).

A literatura precisa ser vista como direito, e a dicotomia literatura erudita/ literatura de cultura de massa afasta esse direito das camadas populares. A democratização da literatura parece dar-se pelo viés daquilo que a torna mais barata, consequentemente, acessível e, enfim, massificada; reconhecer uma visão democrática de leitura, não do cânone, mas de best-seller. A tecnologia e os meios de comunicação tornaram as artes acessíveis. Nesse sentido, pertinentes são as palavras de Culler (1999, p. 53), ao indagar, “o que será do cânone literário se os estudos culturais engolirem os estudos literários? Os estudos culturais não irão matar a literatura através do estímulo ao estudo de filmes, televisão e outras formas culturais populares." Por essa razão, uma dicotomia e rivalidade sem sentido.

Não estamos mais diante de um leitor singular que diante do texto é passivo e age dentro de paradigmas estabelecidos. Se o mercado se tornou eclético é porque, no final das contas, atende a um leitor eclético, que lê as suas próprias preferências e que não apenas se deixa conduzir. Dumont (2000) ressalta que, entre os principais fatores para a mudança de paradigma, é a subjetividade do leitor componente decisivo na interpretação de texto. De recebedor passivo dos conteúdos plurais do texto, com perfil delineado, plano, passa a agente ativo: "Do lado dos leitores, um pouco por toda parte, e qualquer que seja o meio social e cultural, a regra é o ecletismo" (PETIT, 2009, p.73).

Dumont (2000) ainda traça algumas considerações às críticas que têm sido feitas à literatura de cultura de massa através da correspondência dos elementos que imprimem fascínio 
nos leitores. Cada crítico acrescenta seu ponto de vista e delineia seus pressupostos críticos, em linhas gerais, são explicitados e descritos como voltados para o consumo e tendem à homogeneização dos gostos; funcionam como catarse ${ }^{2}$, por proporcionar fuga e evasão, alienando-o a um final feliz; provoca evasão, plantar em romances enigmas para que o leitor desvende-os e sinta a projeção de uma grande descoberta.

As posições favoráveis também deixam claros seus pontos de vista, afirmando, entre tantos argumentos, a necessidade de se considerarem as informações adquiridas com essas leituras. Assim, cada best-seller, por mais que carregue trama semelhante a outras obras de mesma categoria, acrescenta alguma coisa, conforme pontua Ligia:

Seria uma concepção muito simplista da natureza humana pensar que o acúmulo de informações, que a quantidade, não possa se converter em qualidade, pois assim se estaria suprimindo o maior valor de um sujeito, tirando sua capacidade de raciocínio, discernimento e síntese. (DUMONT, 2000, p. 172).

A seleção de textos, as escolhas, dizem respeito, como já discutido, ao porquê de tantas obras e autores. Não daríamos conta das leituras de todas as áreas, até mesmo quando enveredamos por estudos mais voltados a uma área em específico - como Biologia, Química, Língua Portuguesa, entre outras - já nos limitamos a escolhas; e tampouco daríamos conta de cada particularidade dessas áreas: "Quem lê tem de escolher, pois não há literalmente, tempo suficiente para ler tudo, mesmo que não se faça mais nada além disso" (BLOOM, 2001, p. 21). Sejam os clássicos ou não, há sempre que se escolher, e é isso que muitos alunos fazem, escolhem, mas, nem sempre, o cânone.

Na perspectiva de escolhas, a Base Nacional Comum Curricular expressa que o aluno deve

[1]er, de forma autônoma, e compreender - selecionando procedimentos e estratégias de leitura adequados a diferentes objetivos e levando em conta características dos gêneros e suportes - romances, contos contemporâneos, minicontos, fábulas contemporâneas, romances juvenis, biografias romanceadas, novelas, crônicas visuais, narrativas de ficção científica, narrativas de suspense, poemas de forma livre e fixa (como haicai), poema concreto, ciberpoema, dentre outros. (BRASIL, 2017, p.184).

Ao situar o contexto da contemporaneidade, percebe-se claramente a visibilidade a muitas leituras, sobretudo se considerarmos os textos contemporâneos. De certa forma, isso gera uma abertura que coloca o aluno dentro de um contexto de preferência, cuja opinião e apreciação revele um ponto de vista sobre o lido, “expressando avaliação sobre o texto lido e estabelecendo

\footnotetext{
${ }^{2}$ Relacionados a uma estrutura linear, que provoca uma sensação de alívio, onde tudo dá certo. Sensação de realização pelo lido que atinge de maneira rápida e prática os leitores.

Revista Graphos, vol. 22, n² 2, 2020 | UFPB/PPGL | ISSN 1516-1536
} 
preferências por gêneros, temas, autores" (BRASIL, 2017, p. 184). Assim, abarcaria uma visão mais completa dos leitores no seu universo de leituras possíveis.

Portanto, negar o valor da cultura de massa mais parece uma ideologia dominante que, em face de uma grande ameaça, refuta-a ao desprestígio diante de uma eventual concorrente. Não se discute aqui o fim das grandes obras da literatura (clássicos), todavia que somadas a elas existem outras, não que sejam submetidas a um segundo lugar, mas que outras possibilidades sejam reconhecidas. Propomos o reconhecimento do caminho natural descrito por Candido (1988) a partir da elevação sensível das capacidades de cada um, ou seja, fruir o popular e o erudito como um percurso normal, como direito inalienável e tomando a literatura como bem incompressível no sentido pleno, dialógico, político e democrático.

\section{Considerações Finais}

Com este trabalho, buscamos enfatizar o reconhecimento dos leitores e suas subjetividades, bem como a necessidade de ações metodológicas que favoreçam um ensino de literatura pautado no sentido dialógico e democrático dessa arte. Percebemos uma mudança de paradigmas com relação aos leitores e suas preferências, muitas vezes, fortemente influenciados pelo mercado editorial.

Nesse cenário, os best-sellers de cultura de massa surgem como campeões de venda e como leituras consolidadas no repertório do público infantojuvenil. Esses livros chegam às escolas e nem sempre são bem recebidos. Isso se deve pelo desprestígio que a literatura de cultura de massa tem no espaço institucional - local sacralizado pelo cânone.

Por essa razão, defendemos metodologias desenvolvidas pela escola que reconheçam e aproveitem as leituras que os alunos já fazem a fim de ampliar esse repertório de leituras, partindo do conhecido para o desconhecido por eles, de modo que a elevação sensível passe da fruição do popular ao erudito como consequência natural.

\section{Referências}

ABREU, Márcia. Cultura letrada - Literatura e Leitura. São Paulo: Editora Unesp, 2006.

ARAÚJO, Regina Pereira Dau. Formação de leitores e Best-sellers: uma relação possível. Revista travessias, Paraná, v. 8, n. 3, p. 76-87, 2014.

BLOOM, Harold. O cânone ocidental: os livros e a escola do tempo. Tradução: Marcos Santarrita. Rio de Janeiro: Objetiva, 2001.

BOSI, Alfredo. Literatura e resistência. São Paulo: Cia das Letras, 2002. 
BRASIL. Ministério da Educação. Base Nacional Comum Curricular. Brasília, 2017.

CALVINO, Ítalo. Por que ler os clássicos. São Paulo: Companhia das Letras, 1993.

CANDIDO, Antônio. O direito a literatura In: CANDIDO, Antônio. Vários escritos. São Paulo: Ouro sobre Azul, 1998. p. 235-249.

COSSON, Rildo. Entre o cânone e o mercado: a indicação de textos na escola. In: PAULINO, Graça e COSSON, Rildo (org.). Leitura Literária: a mediação escolar. Belo Horizonte: Faculdade de Letras da UFMG, 2014. p. 92-101.

CULLER, Jonathan. Teoria literária: uma introdução. Tradução: Sandra Vasconcelos. São Paulo: Beca Produções Culturais Ltda, 1999.

DUMONT, Ligia Maria Moreira. A opção pela literatura de massa: simples lazer ou alienação? Revista Investigación bibliotecalógica. Minas Gerais, v. 14, n. 28, p. 166-177, jan./jun. 2000.

LIGNANI, Ângela Maria. A recepção crítica de Harry Potter e as estratégias midiáticas de consagração. In: PAULINO, Graça; COSSON, Rildo (org.) Leitura literária: a mediação escolar. Belo Horizonte: Faculdade de Letras da UFMG, 2004. p. 121-130.

LIMA, Shirley de Almeida et al. O Best-seller e a formação do gosto pela leitura dos jovens leitores. Revista Eco-Pós, Goiás, v. 18, n. 1, p. 190-204, 2015.

LIPOVETSKY, Gilles. A Felicidade Paradoxal. São Paulo: Companhia das Letras, 2007.

PAES, José Paulo. A aventura literária: ensaios sobre ficção e ficções. São Paulo:

Companhia das Letras, 2000.

PAZ, Eliane Hatherly. Massa de qualidade. In: I Seminário Brasileiro sobre o Livro e História Editorial, 2004, Casa de Rui Barbosa. Rio de Janeiro.

PETIT, Michèle. Os jovens e a leitura: uma nova perspectiva. Tradução: Celina Olga de Souza. São Paulo: 34, 2008.

REIMÃO, Sandra. Mercado editorial brasileiro 1960-1990. São Paulo: Com-arte; FAPESP, 1996.

RIOLFI, Claudia et al. Ensino de língua portuguesa. São Paulo: Cengage Learning, 2014.

ROSSATO. Wilson. O que é um best-seller?. Revista de Letras. Brasília, ano 01, n. 11, abr.1994.

SODRÉ, Muniz. Best-seller: a literatura de mercado. Rio de Janeiro: Ática, 1988.

Recebido em: 03/05/2020

Aceito para publicação em: 18/09/2020 